\title{
Role of Serum Cystatin-C in Prediction of Acute Kidney Injury in Critical ILL Patients
}

\author{
Mahmoud Maged Hlemy ${ }^{1}$, Gamal Lotfy Abd-Elrahman ${ }^{\mathbf{1}}$, Salama Saad Abd El-lateef ${ }^{2}$, \\ Saeed Mostafa Abd El-hameed ${ }^{1}$, Ahmed Shafek Nabil ${ }^{1}$ \\ ${ }^{1}$ Anesthesia and Intensive Care, and ${ }^{2}$ Clinical Pathology Departments, \\ Faculty of Medicine, Al-Azhar University, Cairo, Egypt \\ Corresponding author: Ahmed Shafek Nabil,email: ahmedshafek123@gmail.com
}

\begin{abstract}
Background: acute kidney injury (AKI) is a syndrome characterized by a rapid (hours to days) deterioration of kidney functions. It is often diagnosed in the context of other acute illnesses and is particularly common in critically ill patients. The clinical consequences of AKI include the accumulation of waste products, electrolytes, and fluid, but also less obvious effects, including reduced immunity and dysfunction of non-renal organs (organ cross-talk). Aim of the Work: was to assess the role of serum Cystatin $C$ in early prediction of Acute Kidney Injury in critically ill patients. Patients and Methods: This a prospective cohort study included a total of 30 critically ill patients who suffered of Acute Kidney Injury and 30 subjects confined to the same age as control, attending at ICU, Al-Azhar University Hospitals. Blood samples were taken for estimation of serum cystatin $\mathrm{C}$ and serum creatinine at (2, 24, 48 and 72 hours). Results: showed that at day zero at 2 hours all patient showed normal kidney functions, and no one has acute kidney injury after 24 hours about 10 patient developed acute kidney injury according to KDIGO classification with a percentage of 33.3\%. after 48 hours all 30 patients developed acute kidney injury according to KDIGO classification with a percentage of $100 \%$ and after 72 hours the patients state began to improve and only 28 patients have acute kidney injury with a percentage of $93.3 \%$ and level of serum creatinine started to decrease to all patients. This was due to treatment and interference to the patients. Conclusion: Cystatin $\mathrm{C}$ level is a valuable biomarker in prediction and early detection of acute kidney injury. Moreover, cystatin $\mathrm{C}$ level may be also used for prognosis of cases of acute kidney injury. Further a large-scale study may be needed to validate its predictive value.
\end{abstract}

Keywords: Serum Cystatin-C, Acute Kidney Injury, Critical ill Patients

\section{INTRODUCTION}

level and urine output are the standard indicators of decreased kidney function despite their known limitations. They have limited sensitivity and specificity and creatinine level change is delayed in response to kidney impairment, thus limiting their usefulness in the early detection of $\mathrm{AKI}^{(3)}$.

Therefore, the need for an accurate and timely biomarker to predict AKI development after renal insult is urgent. Cystatin C (Cys C), a 13-kDa endogenous cysteine proteinase inhibitor, is a member of the family of proteins that has an important role in intracellular catabolism of various peptides and proteins ${ }^{(4)}$.
Acute kidney injury (AKI) is commonly encountered in various patient populations, including critically ill patients, those after cardiac surgery, and those receiving contrast agents. These patients usually have a worse clinical outcome than their non-AKI counterparts ${ }^{(1)}$.

Adverse outcomes include prolonged hospitalization, need for renal replacement therapy, development of chronic kidney disease, and increased mortality rate ${ }^{(\mathbf{1}, 2)}$.

The poor outcome is caused in part by the lack of a timely and accurate biomarker to predict the occurrence of AKI. Currently, serum creatinine ( $\mathrm{SCr}$ ) 
- History of hypertension.

- History of diabetes mellitus.

- History of ischemic heart disease.

The laboratory parameters measured were:

1. Serum creatinine.

2. Serum cystatin C.

3. Arterial blood gasses.

Blood samples were obtained at 2, 24, 48 and 72 hours after admission for estimation of all parameters. Blood was aspirated into two plastic tubes; the first contained no additive for serum separation for measuring creatinine and cystatin $\mathrm{C}$ and the second tube contain heparin for ABG measurement.

1. Creatinine was estimated by colorimetric technique (6) using commercial kits from Beckman coulter company

2. Cystatin $\mathrm{C}$ was estimated by solid phase enzyme linked immunosorbent assay (ELISA) technique ${ }^{(6)}$. Using commercial kit from glory science company

\section{Statistical analysis}

Results were statistically analyzed by SPSS version 20(SPSS Inc., Chicago, IL, USA). Two types of statistics were done.

\section{RESULTS}

This table shows the the general characteristics of the studied groups there was 30 patients 15 of them was males with percentage $50 \%$ of the studied patients and another 15 females with percentage of $50 \%$ of the studied patients and 30 person as control 12 of them was males with percentage $40 \%$ of controls and another 18 females with percentage $60 \%$ of controls. The mean age of patients was $64.83 \pm 9.87$ and the mean age of the controls was $61.03 \pm 6.99$ this table showed that there was no significant difference between the studied group regarding age as $\mathrm{p}$ value was 0.091 and regarding sex also as $\mathrm{p}$ value was 0.436 .
Cys $\mathrm{C}$ is considered to be a good biomarker of decreased kidney function because it is produced at a relatively constant rate and released into plasma, $99 \%$ is filtered by glomeruli and there is no significant protein binding. Numerous studies have evaluated the use of Cys C level as an endogenous marker of kidney function in populations at risk of or with chronic kidney disease, showing that Cys C performs comparably or superior to the diagnostic accuracy of $\mathrm{SCr}$ level in the discrimination of normal from impaired kidney function ${ }^{(5)}$.

The aim of this study was to assess the role of serum Cystatin C in early prediction of Acute Kidney Injury in critically ill patients.

\section{PATIENTS AND METHODS}

This prospective cohort study included a total of 30 critically ill patients who suffered of Acute Kidney Injury and 30 subjects confined to the same age as control, attending at ICU, Al-Azhar University Hospitals. Approval of the ethical committee and a written informed consent from all the subjects were obtained. This study was conducted between September 2017 to June 2018.

Blood samples were taken for estimation of serum cystatin $\mathrm{C}$ and serum creatinine at (2, 24, 48 and 72 hours).

Inclusion criteria: Newly admitted patients (aged above 18 years) to the medical and surgical (ICU)

Exclusion criteria: history of preexisting renal insufficiency or known to be chronic renal failure on regular dialysis. Use of nephrotoxic drugs before or during the study period had obvious anuria, hematuria, rhabdomyolysis or myoglobinuria, Peripheral vascular disease, and Cancerous patients. Patients with ICU length of stay < 3 days.

All of the studied participants were subjected to the following: Full history taking and detailed systemic review with special consideration to the following: 
Table (1): General Characteristics of the studied groups:

\begin{tabular}{|c|c|c|c|c|c|c|}
\hline \multirow[b]{2}{*}{ Characteristics } & \multicolumn{4}{|c|}{ Studied Groups } & \multirow[b]{2}{*}{ Test } & \multirow[b]{2}{*}{$P$ value } \\
\hline & \multicolumn{2}{|c|}{$\begin{array}{l}\text { Patients } \\
(\text { No.=30) }\end{array}$} & \multicolumn{2}{|c|}{$\begin{array}{l}\text { Controls } \\
(\text { No.=30) }\end{array}$} & & \\
\hline Age (years) Mean \pm SD & \multicolumn{2}{|c|}{$64.83 \pm 9.87$} & \multicolumn{2}{|c|}{$61.03 \pm 6.99$} & $\mathbf{t}=1.72$ & 0.091 \\
\hline $\begin{array}{l}\text { Sex } \\
\text { Male } \\
\text { Female }\end{array}$ & $\begin{array}{l}15 \\
15\end{array}$ & $\begin{array}{l}50.0 \\
50.0\end{array}$ & $\begin{array}{l}12 \\
18\end{array}$ & $\begin{array}{l}40.0 \\
60.0\end{array}$ & $\chi^{2}=0.60$ & 0.436 \\
\hline
\end{tabular}

* Significant

This table shows that there was no significant difference between the studied groups regarding age and sex $(\mathrm{P}>0.05)$.

This table shows the clinical characteristics of the studied patient at admission. Regarding heart rate (HR) the range was between 66-101 while the mean was $88.83 \pm 12.87$. Regarding the arterial blood pressure first systolic blood pressure(SBP) the range was between $75-160 \mathrm{mmhg}$ while the mean SBP was $114.33 \pm 37.66 \mathrm{mmhg}$ secondly the diastolic blood pressure (DBP) the range was between $20-110 \mathrm{mmhg}$ while the mean was $67.66 \pm 43.76$ mmhg. Regarding the temperature the range was between 37-39with mean temperature $37.93 \pm 0.90$. The studied patients 24 patients of them was diabetic with percentage of $80 \%$ while there was 23 patients known to be hypertensive with percentage $76.7 \%$ and there was 18 patients known to be ischaemic heart patiens with percentage of $60 \%$.

Table (2): Clinical characteristics of the studied patients:

\begin{tabular}{|l|c|c|}
\hline \multirow{2}{*}{} & \multicolumn{2}{|c|}{$\begin{array}{c}\text { Patients } \\
\text { (No.=30) }\end{array}$} \\
\cline { 2 - 3 } & Mean \pm SD & Range \\
\hline HR (beat/min) & $88.83 \pm 12.87$ & $66-101$ \\
\hline BP & & \\
• SBP (mmhg) & $114.33 \pm 37.66$ & $75-160$ \\
\hline \multirow{2}{*}{ Temperature } & $67.66 \pm 43.76$ & $20-110$ \\
\hline DM & $37.93 \pm 0.90$ & $37-39$ \\
\hline Hypertension & no & 80.0 \\
\hline IHD & 24 & 76.7 \\
\cline { 2 - 3 } & 23 & 60.0 \\
\hline
\end{tabular}

This table shows acute kidney injury among the studied patients at every sample at 2 hours there was no patient had acute kidney injury, at 24 hours there was 10 patients had acute kidney injury with percentage of $33.3 \%$ of the studied patients, at 48 hours all the patients had acute kidney injury with percentage of $100 \%$ and finally at 72 hours there was 28 patients had acute kidney injury with percentage $93.3 \%$.

Table (3): Acute kidney injury among the studied patients:

\begin{tabular}{|c|c|c|}
\hline \multirow{2}{*}{} & \multicolumn{2}{|c|}{$\begin{array}{c}\text { Patients } \\
\text { (No.=30) }\end{array}$} \\
\cline { 2 - 3 } & \multicolumn{2}{|c|}{ \%o } \\
\hline AKI & 0 & 0.0 \\
At 2 hours & 10 & 33.3 \\
At 24 hours & 30 & 100.0 \\
At 48 hours & 28 & 93.3 \\
At 72 hours & & \\
\hline
\end{tabular}


This table shows the serum creatinine of the studied groups the serum creatinine at 2 hours was $0.91 \pm 0.17 \mathrm{mg} / \mathrm{dl}$, at 24 hours was $1.37 \pm 0.20 \mathrm{mg} / \mathrm{dl}$, at 48 hours was $1.91 \pm 0.21$ $\mathrm{mg} / \mathrm{dl}$ and at 72 hours was $1.71 \pm 0.18 \mathrm{mg} / \mathrm{dl}$ the table shows there was significant difference between the studied groups regarding creatinine $(\mathrm{p}<.001)$.

Table (4): Creatinine ( $\mathrm{mg} / \mathrm{dl})$ of the studied groups:

\begin{tabular}{|l|c|c|c|c|}
\hline \multirow{2}{*}{} & \multicolumn{4}{|c|}{ Creatinine } \\
\cline { 2 - 5 } & At 2 hours & At 24 hours & At 48 hours & At 72 hours \\
\hline Patients & $0.91 \pm 0.17$ & $1.37 \pm 0.20$ & $1.91 \pm 0.21$ & $1.70 \pm 0.18$ \\
\hline Controls & $0.72 \pm 0.09$ & - & - & - \\
\hline $\begin{array}{l}\text { Independent t test } \\
\text { P value }\end{array}$ & 5.20 & - & - & - \\
\hline Paired t test & $<0.001^{*}$ & & & 18.93 \\
\hline P value & & 11.93 & 23.92 & $<0.001^{*}$ \\
\cline { 3 - 5 }
\end{tabular}

This table shows that there was significant difference between the studied groups regarding creatinine $(\mathrm{P}<0.001 *)$.

This table shows the serum cystatin $\mathrm{c}$ of the studied groups at 2 hours the cystatin $\mathrm{c}$ was $1.44 \pm 0.24 \mathrm{mg} / \mathrm{L}$, at 24 hours the cystatin c was $1.57 \pm 0.25 \mathrm{mg} / \mathrm{L}$, at 48 hours the cystatin $\mathrm{c}$ was $1.53+0.22 \mathrm{mg} / \mathrm{L}$ and at 72 hours the cystatin $\mathrm{c}$ was $1.42 \pm 0.20 \mathrm{mg} / \mathrm{L}$ this table shows there was significant difference between the studied groups regarding cystatin $\mathrm{c}(\mathrm{p}<.001)$ and also shows that there was significant difference among patients at different time sequences $(\mathrm{p}<.001)$.

Table (5): Cystatin C (mg/L) of the studied groups:

\begin{tabular}{|l|c|c|c|c|}
\hline \multirow{2}{*}{} & \multicolumn{4}{|c|}{ Cystatin } \\
\cline { 2 - 5 } & At 2 hours & At 24 hours & At 48 hours & At 72 hours \\
\hline Patients & $1.44 \pm 0.24$ & $1.57 \pm 0.25$ & $1.53 \pm 0.22$ & $1.42 \pm 0.20$ \\
\hline Controls & $0.91 \pm 0.05$ & - & - & - \\
\hline $\begin{array}{l}\text { Independent t test } \\
\text { P value }\end{array}$ & 11.72 & - & - & - \\
\hline Paired t test & $<0.001^{*}$ & - & 2.60 & 0.53 \\
\hline P value & & 6.57 & $0.014^{*}$ & 0.596 \\
\cline { 3 - 5 }
\end{tabular}

This table shows that there was significant difference between the studied groups regarding cystatin $\mathrm{C}(\mathrm{P}<0.001 *)$. This table shows that there was significant difference among patients at different time sequence $(\mathrm{P}<0.001)$.

This table shows $\mathrm{PH}$ of the studied patients from arterial blood gases at 2 hours $\mathrm{PH}$ was7.36 \pm 0.05 , at 24 hours $\mathrm{PH}$ was $7.37 \pm 0.05$, at 48 hours $7.34 \pm 0.04$ and at 72 hours $\mathrm{PH}$ was7.37 \pm 0.03 this table shows that there was no significant difference regarding $\mathrm{PH}$ at different time sequences $(\mathrm{p}>0.05)$.

Table (6): PH of the studied patients:

\begin{tabular}{|l|c|c|c|c|}
\hline \multirow{2}{*}{ PH } & At 2 hours & At 24 hours & At 48 hours & At 72 hours \\
\cline { 2 - 5 } & $7.36 \pm 0.05$ & $7.37 \pm 0.05$ & $7.34 \pm 0.04$ & $7.37 \pm 0.03$ \\
\hline Paired t test & & 0.52 & 1.58 & 0.51 \\
\cline { 1 - 3 } P value & & 0.603 & 0.123 & 0.610 \\
\hline
\end{tabular}

This table shows that there was no significant difference regarding PHat different time sequence $(\mathrm{P}>0.05)$.

This table shows th $\mathrm{PCO} 2$ of the studied patients from arterial blood gases at 2 hours PCO2 was $40.36 \pm 11.94$, at 24 hours the PCO2 was $37.93 \pm 8.22$, at 48 hours the PCO2 was 
$37.43 \pm 6.05$ and at 72 hours the PCO2 was $39.46 \pm 6.62$ this table shows that there was no significant difference regarding PCO2 at different time sequence ( $>0.05)$.

Table (7): PCO2 of the studied patients:

\begin{tabular}{|l|c|c|c|c|}
\hline \multirow{2}{*}{ PCO2 } & At 2 hours & At 24 hours & At 48 hours & At 72 hours \\
\cline { 3 - 5 } & $40.36 \pm 11.94$ & $37.93 \pm 8.22$ & $37.43 \pm 6.05$ & $39.46 \pm 6.62$ \\
\hline Paired t test & & 1.51 & 1.66 & 0.53 \\
\cline { 1 - 4 } P value & & 0.140 & 0.107 & 0.597 \\
\hline
\end{tabular}

This table shows that there was no significant difference regarding $\mathrm{PCO} 2$ at different time sequence $(\mathrm{P}>0.05)$.

This table shows the HCO3 of the studied patients from athe arterial blood gases the $\mathrm{HCO} 3$ at 2 hours was $22.83 \pm 6.37$, at 24 hours $\mathrm{HCO} 3$ was $21.61 \pm 4.64$,at 48 hours the $\mathrm{HCO} 3$ was $20.83 \pm 4.29$ and at 72 hours the $\mathrm{HCO} 3$ was $22.74 \pm 4.51$ the table shows that there was no significant difference regarding $\mathrm{HCO} 3$ at different time sequences ( $>0.05)$.

Table (8): $\mathrm{HCO} 3$ of the studied patients:

\begin{tabular}{|l|c|c|c|c|}
\hline \multirow{2}{*}{ HCO3 } & At 2 hours & At 24 hours & At 48 hours & At 72 hours \\
\cline { 2 - 5 } & $22.83 \pm 6.37$ & $21.61 \pm 4.64$ & $20.83 \pm 4.29$ & $22.74 \pm 4.51$ \\
\hline Paired t test & & 1.46 & 1.60 & 0.08 \\
\cline { 1 - 3 } P value & & 0.155 & 0.120 & 0.929 \\
\hline
\end{tabular}

This table shows that there was no significant difference regarding PCO2at different time sequence $(\mathrm{P}>0.05)$.

This table shows the correlation between cystatin $\mathrm{c}$ and creatinine and arterial blood gases among the studied patients the table shows that there wan no significant correlation between cystatin $\mathrm{c}$ and creatinine among the studied patients $(\mathrm{p}>0.05)$ in another words elevation cystatin $\mathrm{c}$ was not accompanied by elevation of creatinine the elevation of cystatin c happened while creatinine was normal, this table also shows thee was no correlationbetween cystatin and ABGS ( $\mathrm{p}>0.05)$.

Table (9): Correlation between Cystatinc and Creatinine and arterial Blood gases among the studied patients:

\begin{tabular}{|l|c|c|c|c|c|c|c|c|}
\hline \multirow{2}{*}{} & \multicolumn{9}{|c|}{ Cystatin C (mg/dl) } \\
\cline { 2 - 9 } & \multicolumn{2}{|c|}{ At 2 hours } & \multicolumn{2}{c|}{ At 24 hours } & \multicolumn{2}{c|}{ At 48 hours } & \multicolumn{2}{c|}{ At 72 hours } \\
\cline { 2 - 9 } & r & P value & r & P value & R & P value & r & P value \\
\hline Creatinine(mg/dl) & 0.16 & 0.390 & -0.04 & 0.824 & 0.08 & 0.654 & -0.11 & 0.536 \\
\hline PH & -0.026 & 0.893 & -0.11 & 0.546 & -0.21 & 0.262 & -0.01 & 0.931 \\
\hline PCO2 & -0.165 & 0.383 & -0.23 & 0.203 & 0.36 & 0.046 & 0.15 & 0.415 \\
\hline HCO3 & -0.292 & 0.117 & -0.26 & 0.161 & 0.24 & 0.197 & 0.23 & 0.222 \\
\hline
\end{tabular}

This table shows that that there was no significant correlation between cystatin $\mathrm{C}$ and creatinine and $\mathrm{ABGs}(\mathrm{P}>0.05)$.

This table shows the validity of cystatin $\mathrm{c}$ and creatinine this table shows that sensitivity, specificity and accuracy of cystatin c was $100 \%$ while shows that creatinine sensitivity was $77 \%$, specificity of creatinine was $73 \%$ and accuracy of creatinine was $75 \%$ which means that cystatin $\mathrm{c}$ is more sensitive and specific than creatinine in early detection of acute kidney injury. 
Table (10): Validity of creatinine and cystatinc;

\begin{tabular}{|l|c|c|c|c|c|c|c|}
\hline & AUC & Cutoff point & Sensitivity \% & Specificity \% & $\begin{array}{c}\text { Accuracy } \\
\%\end{array}$ & PPV \% & NPV\% \\
\hline Creatinine(mg/dl) & 0.812 & 0.78 & 0.77 & 0.73 & 75.0 & 74.0 & 76.0 \\
\hline Cystatin C(mg/L) & 1.0 & 1.04 & 100.0 & 100.0 & 100.0 & 100.0 & 100.0 \\
\hline
\end{tabular}
kidney injury.

Cystatin $\mathrm{C}$ is more sensitive and specific than creatinine in early detection of acute

\section{DISCUSSION}

function (specially gender, muscle mass, age) than creatinine ${ }^{(10)}$.

In the current study we sought to evaluate the role of cystatin $\mathrm{C}$ in predicting and early detecting of acute kidney injury in critical ill patients in intensive care unit (ICU). We hypothesized that serum cystatin $\mathrm{C}$ would mark AKI more accurately than serum creatinine in heterogeneous sample of patients presented to ICU. In order to investigate the accuracy of serum cystatin $\mathrm{C}$ in early detection of AKI, we conducted a prospective cohort study at Al-Azhar university hospitals from September 2017 to June 2018, 30 patients admitted to ICU were included in this study with 30 subjects confined to the same age as control. Blood samples were taken for estimation of serum cystatin $\mathrm{C}$ and serum creatinine at $(2,24,48$ and 72 hours). The present study showed that at day zero at 2 hours all patient showed normal kidney functions and no one has acute kidney injury after 24 hours about 10 patient developed acute kidney injury according to KDIGO classification with a percentage of $33.3 \%$ after 48 hours all 30 patients developed acute kidney injury according to KDIGO classification with a percentage of $100 \%$ and after 72 hours the patients state began to improve and only 28 patients have acute kidney injury with a percentage of $93.3 \%$ and level of serum creatinine started to decrease to all patients this was due to our treatment and interference to the patients.

The present study showed that serum cystatin $\mathrm{C}$ was highly significant in early prediction of acute kidney injury at early phase as it showed significant
Acute kidney injury (AKI) is a common problem in critically ill patients and is independently associated with increased morbidity and mortality ${ }^{(7)}$. In a large heterogeneous cohort study of critically ill patients, the incidence of AKI was about $36 \%$ among intensive care unit (ICU) patients. The diagnosis of AKI is currently delayed and inaccurate, which largely contributes to the poor clinical outcomes of AKI and results in great challenges in preventing and treating this kidney disease worldwide ${ }^{(7)}$. Serum or plasma creatinine is the most common marker of glomerular filtration rate (GFR).

Despite its common use, creatinine has limitation as a marker for renal function due to the inter-individual variation in muscle mass, delayed rise after renal insult, and tubular secretion of creatinine ${ }^{(8)}$. The rise in serum creatinine is known to occur relatively late in the course of AKI and hence cannot be used to initiate potentially effective therapies in preventing or treating AKI during phases when the injury may be potentially reversible. The lack of early biomarkers for acute kidney injury has prevented timely interventions to mitigate the effects of acute kidney injury (9). Recently, another biomarker for functional injury of the kidney (cystatin C) has been shown to be used in early detection of renal function impairment. It has some advantages over the creatinine. It is produced by all nucleated cells and freely filtered by the glomerular membrane, entirely catabolized by proximal tubule, without secretion, and serum concentration of cystatin $\mathrm{C}$ is determined by GFR. Cystatin C is less dependent on factors other than renal 
decreased at the fourth sample taken after $72 \mathrm{~h}$ to reach only 28 patients rather than 30 patients at the third sample taken after $48 \mathrm{~h}$ which means also that serum cystatin $\mathrm{C}$ level can also predict improvement, recovery and prognosis of the cases with acute kidney injury which is also in agreement with Gharaibeh et al. ${ }^{(11)}$ who declared that the serum cystatin $\mathrm{C}$ has an important role in prediction of acute kidney injury and another role in recovery from acute kidney injury as it declared that cystatin $\mathrm{C}$ rises one to two days before rise of creatinine and also it decreases by at least on day before decline of creatinine which explained by during early phase of acute kidney injury glomerular filtration rate is significantly affected but has not enough time for creatinine to accumulate and rise and so serum creatinine level can not express accurately kidney injury and the estimated glomerular filtration rate(eGFR) over estimate the real glomerular filtration rate this is also happens during early phase of recovery when serum creatinine is still high and don`t reflect glomerular filtration rate (GFR) accurately and in this case the estimated glomerular filtration rate (eGFR) underestimate the real glomerular filtration rate (GFR) ${ }^{(\mathbf{1 2})}$.

The results also showed that either age or gender was not statistically significant in either acute kidney injury or serum cystatin $\mathrm{C}$ level which is in the same line with Kankare et al. ${ }^{(13)}$ who reported that serum cystatin $\mathrm{C}$ is a better marker of renal function in early stages of AKI and is less affected by age, gender, muscle mass, and ethnicity. Use of serum cystatin C-based GFR may be more accurate and useful for early therapeutic intervention and possibly a favorable outcome. From the study and results we can conclude that serum cystatin $\mathrm{C}$ seems to be a good early biomarker for early prediction and detection of acute kidney injury which is in agreement with $\boldsymbol{H u}$ et al. (14) who showed that the sCys $\mathrm{C}$ can serve as an early predictor for the development of AKI in critical care unit elevation from the $1^{\text {st }}$ sample at 2 hours with mean value $1.44 \pm 0.24 \mathrm{mg} \backslash \mathrm{dl}$ compared $0.91 \pm 0.05 \mathrm{mg} \backslash \mathrm{dl}$ for control group. A cut off value for cystatin $\mathrm{C}$ of $1.04 \mathrm{mgldl}$ was predictive for development of acute kidney injury with sensitivity $100 \%$ and specificity $100 \%$. Regarding serum creatinine the study showed that there was significant between the studied groups but serum creatinine started to elevate from the $2^{\text {nd }}$ sample at 24 hours with mean value of $1.37 \pm 0.20 \mathrm{mgldl}$ and reached its peak at the $3^{\text {rd }}$ sample with mean value of $1.91 \pm 0.21 \mathrm{mg} / \mathrm{dl}$ with sensitivity $77 \%$ and specificity $73 \%$.

According to results showed that there was no significant correlation between serum cystatin $C$ and creatinine in another words elevation of serum cystatin $\mathrm{C}$ occurred while level of serum creatinine was still within normal values that is in the same line with Herget-Rosenthal et al. ${ }^{(3)}$ who found that use of serum cystatin $\mathrm{C}$ is more beneficial than serum creatinine in prediction of acute kidney injury and it declared that serum cystatin $\mathrm{C}$ predict acute kidney injury one to two days earlier than serum creatinine and his explanation of this was that serum cystatin $\mathrm{C}$ reflects changes in glomerular filtration rate(GFR) more rapidly than serum creatinine reflex it which is due to alterations of glomerular pore size which affect glomerular filteration of creatinine and cystatin $\mathrm{C}$ and make difference between them during acute renal affection.

According to study results, serum cystatin predicted the prognosis and improvement of acute kidney injury before creatinine as at the third sample taken after $48 \mathrm{~h}$, the mean value of serum cystatin $\mathrm{C}$ decreased to reach $1.53 \pm 0.22 \mathrm{mg} / \mathrm{dl}$ rather than $1.57 \pm 0.25 \mathrm{mgldl}$ at the second sample taken after $24 \mathrm{~h}$ to reach $1.42 \pm 0.20 \mathrm{mgldl}$ in the fourth sample taken after $72 \mathrm{~h}$ while the level of creatinine started to decrease in the fourth sample taken after $72 \mathrm{~h}$ to reach mean value of $1.70 \pm 0.18 \mathrm{mg} / \mathrm{dl}$ rather than the third sample taken after $48 \mathrm{~h}$ mean value which was $1.91 \pm 0.21 \mathrm{mg} \backslash \mathrm{dl}$ and the number of patients had acute kidney injury 
before serum creatinine levels started rising, Serum cystatin $\mathrm{C}$ has a higher sensitivity in identifying early kidney dysfunction, which is missed by relying on serum creatinine alone which explained by GFR in critical ill patients changes rapidly and this changes takes up to several days to appear on serum creatinine as creatinine have blind area in which creatinine $\mathrm{c}$ which occurs in mild to moderate decrease in GFR which ranges between 40 to $70 \mathrm{ml} \backslash \mathrm{min} \backslash 1.73 \mathrm{~m} 2$ so early reduction of GFR cannot be assessed by creatinine while cystatine $\mathrm{c}$ has no blind area so can assess early changes of GFR so creatinine will give false negative results of GFR while cystatin $\mathrm{C}$ will give true positive results regarding GFR ${ }^{(21)}$.

Some studies showed that the combined use of serum cystatin $\mathrm{C}$ and serum creatinine both are essential for diagnosis of occurrence of acute kidney injury like ${ }^{(22)}$ which demonstrated that use of both serum cystatin $\mathrm{C}$ and serum creatinine was more beneficial than use one of them only for detection of acute kidney injury but it also declared that serum cystatin $\mathrm{C}$ has more predictive power than serum creatinine. On the other hand the study results was in disagreement with some studies like Bongiovanni et al. (23) which declared that Compared with the traditional markers of serum creatinine and glomerular filtration rate (GFR), cystatin C did not show any advantage for the prediction of acute kidney injury and in addition the combined use of serum cystatin $\mathrm{C}$, serum creatinine and glomerular filtration rate(GFR) had shown the best results for prediction of acute kidney injury the disagreement may be due to the rely on RIFLE classification which depends more on glomerular filtration rate which may be affected rapidly but serum creatinine used in estimation of glomerular filtration rate (GFR) is in accurate in its estimation and may under estimate it due to tubular secretion and reabsorption of creatinine and published glomerular filtration rate (GFR) formulas can be used when kidney functions are stable but they patients, as well as their short-term prognosis. If confirmed further, serum cystatin $\mathrm{C}$ may provide a unique opportunity to impact dramatically the management of AKI by delivering diagnostic, severity, and prognostic information at an early time-point following a renal insult which is explained by him as cystatin $\mathrm{C}$ production is stable process cannot be affected by renal conditions. protein catabolism and diet and it doesn't change according to age or body mass unlike creatinine which is affected by body mass and diet, also biochemical characteristics of cystatin $\mathrm{C}$ allow its freely filtration through renal glomeruli and metabolized and reabsorbed by proximal tubules while creatinine is secreted by renal tubules which contributes of $20 \%$ of total creatinine excretion by the kidney and this percentage may be increased if kidney affected so due to all these factors creatinine may not be useful as a good parameter for accurate determination of GFR while cystatin $C$ has been suggested to be an ideal biomarker for GFR ${ }^{(15)}$. And this study is in the same line with Zhang et al. (16) which indicated that serum cystatinc has a good biomarker value in prediction of AKI than serum creatinine and also indicates that urinary cystatin $\mathrm{C}$ has a moderate diagnostic value due to affection of its urinary excretion. Also the study is compatible with Zand et al. ${ }^{(17)}$ which demonstrated thatearly serum cystatin C level (within 24 hours after ICU admission) has prognostic value in predicting AKI during the first week of ICU admission and estimation of mortality during ICU admission. This study also agreed with Nejat et al. ${ }^{(18)}$ who declared that cystatin $\mathrm{C}$ is an effective and early biomarker than creatinine in detection of AKI. This study agree also with Yong et al. ${ }^{(19)}$ who said that cystatin $\mathrm{C}$ will be an excellent marker not only for chronic kidney disease (CKD) diagnosis but also for AKI prediction.also the study agreed with Murty et al. ${ }^{(20)}$ who demonstrated that serum cystatin $\mathrm{C}$ was elevated much 
Moreover, cystatin $\mathrm{C}$ level may be also used for prediction for prognosis of cases of acute kidney injury. Further a largescale study may be needed to validate its predictive value.

\section{REFERENCES}

1. Wald R, Quinn RR, Luo J et al. (2009): Chronic dialysis and death among survivors of acute kidney injury requiring dialysis. JAMA., 302:1179-1185.

2. Bagshaw SM, George C, Dinu I, Bellomo R (2008): A multi-centre evaluation of the RIFLE criteria for early acute kidney injury in critically ill patients. Nephrol Dial Transplant., 23:1203-10.

3. Herget-Rosenthal S, Marggraf G, Hüsing $\mathrm{J}$ et al. (2004): Early detection of acute renal failure by serum cystatin C. Kidney Int., 66:1115-1122.

4. Barrett AJ, Davies ME, Grubb A (1984): The place of human gamma-trace (cystatin C) amongst the cysteine proteinase inhibitors. Biochem Biophys Res Commun., 120:631-636.

5. Roos JF, Doust J, Tett SE, Kirkpatrick CM (2007): Diagnostic accuracy of cystatin C compared to serum creatinine for the estimation of renal dysfunction in adults and children: a metaanalysis. Clin Biochem., 40:383391.

6. Larry J and Kricka D (1996): Principle of immunochemical techniques, Fundamentals of Clinical Chemistry. Tietz WWW foueth edition. Ch 10 P 149 Sande3rs Company Philadelphia.

7. Uchino S, Kellum JA, Bellomo R, Doig GS, Morimatsu H, Morgera $S$ et al. (2005): Acute renal failure in critically ill patients: a multinational, are in accurate when kidney functions are decreasing or increasing ${ }^{(24)}$ than rely on KDIGO classification in our study which is more recent and updated and depend on degree of increase of serum creatinine to base line creatinine only and don't depend on glomerular filtration rate (GFR). This study is also in disagreement with Knight et al. ${ }^{(25)}$ which demonstrated that serum cystatin $\mathrm{C}$ is affected by other factors e.g. body weight and smoking and Serum cystatin $\mathrm{C}$ based estimates of renal function don't appear to be superior to creatinine based estimate renal measurement of creatinine clearance and assessment of acute kidney injury by RIFLE classification not KDIGO classification used in our study.

This study had some limitations: first, we used serum creatinine as the gold standard for determination of AKI by KDIGO classification. Second, full renal evaluation by pelvi-abdominal ultrasound, albumin-creatinine ratio and renal isotopic scan for better correlation with serum cystatin $\mathrm{C}$ however all patients had a normal kidney functions and we could not add any financial burden in an academic non-profitable institute. Third it is a single center study, so our results must be validated in larger multicenter studies to validate the predictive value of cystatin $C$. fourth we excluded the patients with history of CKD in the study which explains the lower rate of CKD patients in our study. Fifth serum cysatin c may be affected by neoplasms as it is excreted from nucleated cells which may be affected by neoplasms ${ }^{(26)}$ which explain absence of these patients from our study. Sixth the level of cystatin C may be lower than the level attained in other studies (1.2 $\mathrm{mg} \backslash \mathrm{L})$. This is may be due to method of analysis (ELISA in our study while Turbidimetric method in the other studies).

\section{CONCLUSION}

As far as demonstrated cystatin $\mathrm{C}$ level is a valuable biomarker in prediction and early detection of acute kidney injury in intensive care unit (ICU) patients. 
16. Zhang $Z$, Lu B, Sheng $X$, Jin $N$ (2011): Cystatin $C$ in prediction of acute kidney injury: a systemic review and meta-analysis. American Journal of Kidney Diseases, 58(3):356-65.

17. Zand F, Sabetian G, Abbasi G, Rezaianzadeh A, Salehi A, Khosravi A, Geramizadeh B, Taregh SU, Javadpour S (2015): Early Acute Kidney Injury based on serum creatinine or cystatin $\mathrm{C}$ in intensive care unit after major trauma. Iranian journal of medical sciences, 40(6):485.

18. Nejat M, Pickering JW, Walker RJ, Endre ZH (2010): Rapid detection of acute kidney injury by plasma cystatin $\mathrm{C}$ in the intensive care unit. Nephrol Dial Transplant., 25:3283-9.

19. Yong Z, Pei X, Zhu B, Yuan H, Zhao W (2017): Predictive value of serum cystatin $\mathrm{C}$ for acute kidney injury in adults: a meta-analysis of prospective cohort trials. Scientific Reports, 7:41012.

20. Murty MS, Sharma UK, Pandey VB, Kankare SB (2013): Serum cystatin $\mathrm{C}$ as a marker of renal function in detection of early acute kidney injury. Indian journal of Nephrology, 23(3):180.

21. Hoek FJ, Kemperman FA and Krediet RT (2003): A comparison between cystatin $\mathrm{C}$, plasma creatinine and the Cockcroft and Gault formula for the estimation of glomerular filtration rate. Nephrol Dial Transplant., 18: 2024-31.

22. Soto K, Coelho S, Rodrigues B, Martins H, Frade F, Lopes S, Cunha L, Papoila AL, Devarajan P (2010): Cystatin C as a marker of acute kidney injury in the emergency department. Clinical Journal of the American multicenter study. JAMA., 294:813-8.

8. Nguyen MT, Devarajan $P$ (2008): Biomarkers for the early detection of acute kidney injury. Pediatr Nephrol., 23:2151-7.

9. Cruz DN, Ronco $C$ and Katz $N$ (2010): Neutrophil gelatinaseassociated-lipocalin: apromising biomarker for detecting cardiac surgery,associated acute kidney injury. J Thorac Cardiovasc Surg., 139.

10. Risch L and Huber AR (2005): Assessing glomerular filtration rate in renal transplant recipients by estimates derived from serum measurements of creatinine and cystatin C. Clin Chim Acta., 356:204-11.

11. Gharaibeh KA, Hamadah AM, ElZoghby ZM, Lieske JC, Larson TS, Leung N (2018): Cystatin C Predicts Renal Recovery Earlier Than Creatinine among Patients With Acute Kidney Injury. Kidney International Reports, 3(2):337-42.

12. Stevens LA and Levey AS (2005): Measurement of kidney function. Med Clin North Am., 89: 457-73

13. Kankare SB, Murty MSN, Pandey VB, Sharma UK (2013): Indian Journal of Nephrology, 23(3).

14. Hu Y, Liu H, Du L, Wan J, Li X (2017): Serum Cystatin C Predicts AKI and the Prognosis of Patients in Coronary Care Unit: a Prospective, Observational Study. Kidney and Blood Pressure Research; 42(6):961-73.

15. Randers E, Erlandsen EJ, Pedersen OL, Hasling C, Danielsen $H$ (2000): Serum cystatin $C$ as an endogenous parameter of the renal function in patients with normal to moderately impaired kidney function. Clin Nephrol., 54:203-9. 
25. Knight EL, Verhave JC, Spiegelman D et al. (2004): Factors influencing serum cystatin $\mathrm{C}$ levels other than renal function and the impact on renal function measurement. Kidney Int., 65: 1416-21.

26. Seronie-Vivien $S$, Delanaye $P$, Pieroni L, Mariat C, Froissart M, Cristol JP (2005): SFBC "Biology of renal function and renal failure" working group: Cystatin C: Current position and future prospects. Clin Chem Lab Med., 46: 1664-1686.
Society of Nephrology, 5(10):1745-54.

23. Bongiovanni C, Magrini L, Salerno G, Gori CS, Cardelli P, Hur M, Buggi M, Di Somma S (2015): Serum cystatin $C$ for the diagnosis of acute kidney injury in patients admitted in the emergency department. Disease Markers. doi: $10.1155 / 2015 / 416059$.

24. Rule AD, Bergstralh EJ, Slezak JM et al. (2006): Glomerular filtration rate estimated by cystatin $\mathrm{C}$ among different clinical presentations. Kidney Int., 69: 399-405. 